\title{
LA TRANSFORMACIÓN DEL ESTADO REGIONAL ITALIANO. LAS MODIFICACIONES INTRODUCIDAS POR LAS ÚLTIMAS REFORMAS CONSTITUCIONALES (II)
}

\author{
Silvio Gambino*
}

RESUMEN: El modelo regional italiano, fijado por la Constitución de 1948, ha destacado tradicionalmente como referente en los procesos de descentralización política propios de un Estado unitario. El presente ensayo intenta explicar cómo las recientes leyes de reforma constitucional (Leyes núm. 1/1999, 2/2001 y 3/2001) han transformado dicho modelo de distribución territorial del poder. Luego de explicar las bases fundamentales de la regulación constitucional ( $y$ en particular los resguardos en favor de la igualdad), el análisis se centra en la estructura y poderes de los órganos de gobierno, en el reparto modificado de las competencias normativas a nivel estatal, regional y local, como asimismo en el desarrollo de la autonomía financiera de los entes territoriales. Como no puede ser de otro modo, el estudio no desprecia la atención hacia ciertos factores estructurales (políticos $y$, muy especialmente, socioeconómicos) que condicionan el desarrollo de las competencias reconocidas por la Constitución y los estatutos. De la combinación de estos distintos elementos se concluye que, en términos comparativos, el proceso italiano de reformas se define con una identidad propia que no permite, sin caer en el error, la asimilación con otros modelos de articulación territorial, como son por ejemplo el federalismo, la devolution en el Reino Unido o el autonomismo español.

Palabras Clave: Regional - Italia - Descentralización - Reparto de Competencias - Reforma.

ABSTRACT: The Italian regional Model, set by the Constitution of 1948 , has been traditionally presented as a paradigm of political decentralization among unitary States. This essay intends to explain how the recent Constitutional Reform (Acts 1/1999, 2/2001 y 3/2001) transformed such

- Profesor Ordinario de Derecho Público Comparado, y Decano de la Facultad de Ciencias Políticas, Universidad de Calabria, Italia. Traducción de Manuel A. NúÑez Poblete y Vicente A. Sanjurjo Rivo.

Artículo recibido el 4 de agosto de 2004. Aprobado por el Comité Editorial el 14 de diciembre de 2004.

Se ofrece la segunda parte de este trabajo publicado en su primera sección en la Revista de Derecho correspondiente al Año $12 \mathrm{~N}^{\circ} 1$, abril 2005. 
territorial model. After a broad explanation of the main constitutional regulations, the analysis focuses in the structure and powers of government agencies, in the modified allocation of competences at state, regional and local level, as well as in financing autonomy. Attention is also payed on certain structural causes (political and, very specially, socio-economic ones) which have been determinant for the development of competences recognized by the Constitution and the statutes. Finally, from a comparative approach, the Italian reform can be defined as a pattern with own identity. It cannot be assimilated with other models of territorial allocation of power, such a federalism, british devolution or Spanish autonomy.

KEY wORDS: Regional - Italy - Decentralization - Apportionment of Competencies - Reform.

SUMARIO: 1. Las instituciones regionales (y las autonomías locales): Principios y disciplina constitucional. 2. Las regiones en la Constitución de 1948. 3. Las regiones y los entes locales entre modelo constitucional y sistema político: una especificidad italiana (aunque no solo). 4. La arquitectura institucional y el sistema normativo del nuevo Título $V$ de la Constitución. 4.1. Fuentes regionales (Estatuto, leyes, reglamentos regionales). 4.1.1. Estatutos y forma de gobierno regional (formas de investidura del Presidente de la Junta regional, relaciones entre Legislativo y Ejecutivo, debilitamiento del papel del Consejo). 4.1.2. El referéndum (de confirmaciónloposición) en el procedimiento de aprobación de los Estatutos regionales. 4.1.3. La potestad legislativa y reglamentaria de las regiones. 4.1.4. Los límites de la potestad legislativa regional (en particular, en materia de contenidos esenciales de los derechos civiles y sociales). 4.1.5. Perspectivas (ulteriores y problemáticas) de la reforma de la reforma: la denominada devolution a la italiana. 4.2. Fuentes locales. 4.3. La autonomía financiera de las autonomías territoriales. Bibliografía esencial.

\section{LA ARQUiTECTURA INSTITUCIONAL Y EL SISTEMA NORMATIVO DEL Nuevo Título V de la Constitución}

Las leyes constitucionales de revisión del Título $\mathrm{V}$ han remodelado el conjunto de la arquitectura institucional, además del sistema de fuentes del ordenamiento republicano. En cuanto a su definición, estas reformas no pueden reconducirse a modelos federales, ya que en realidad se limitan a constituir un "arquitrabe" constitucional necesario para consolidar y para asegurar "armonía" a la larga serie de acciones legislativas que a lo largo de la década de los noventa han incidido en el ordenamiento regional (y en el de las autonomías locales).

En este sentido, la definición más convincente del nuevo ordenamiento territorial es la de "República de las autonomías". A diferencia 
de los dos primeros procesos de regionalización (1972 y 1977) e incluso del tercero (Ley núm. 59/1997 y respectivos decretos de ejecución), las reformas constitucionales territoriales constituyen la realización de los principios constitucionales relativos a la autonomía y al pluralismo. Estos principios, en las nuevas formas de la valoración de la competencia legislativa de las regiones y de la propia autonomía normativa local, verifican el principio democrático y pluralista, además de los de eficacia, responsabilidad, y transparencia de los poderes públicos.

Por tanto, las reformas se presentan como un "desarrollo" de los principios constitucionales y en modo alguno como una superación del principio de la unidad y de la indivisibilidad, lo que constituiría una solución constitucionalmente inviable, dada la naturaleza inviolable e inderogable de tales principios.

Las innovaciones aportadas por las reformas no son nada desdeñables, en cuanto que han sido "actualizados" valores y principios que ya contenía la Constitución de 1948, pero que habían permanecido confinados en una forma excesivamente deudora del Estado liberal dieciochesco. Respecto a los principios constitucionales, la dinámica de las "reformas territoriales" y la consiguiente ordenación de las fuentes se deben reconducir, en consecuencia, hacia una plena ejecución de la Constitución, después de una "congelación" de varias décadas en las que aquella había estado sometida a la "constitución material" del país (de hecho las regiones ordinarias, aunque previstas en la Constitución, solo han sido efectivamente puestas en marcha desde 1972 y posteriormente, de forma completa, a partir de 1977).

La nueva formulación del artículo 114 de la Constitución constituye un nuevo pacto constitucional, en virtud del cual la República ya no se divide en regiones, provincias y ayuntamientos (tal y como se preveía en el texto constitucional vigente), sino que "se constituye por los ayuntamientos, las provincias, las ciudades metropolitanas, las regiones y el Estado" (con una evidente inversión del sujeto legitimado para el ejercicio de los poderes).

La modificación del artículo 114, junto a la del artículo 118 de la Constitución, hace explícito y plenamente operativo todo cuanto había ya sido materialmente introducido en el ordenamiento por las llamadas reformas Bassanini (leyes núms. 59/1997, 127/1997, 191/1998, 50/1999). Con estas modificaciones constitucionales, además, se lleva a efecto la formal constitucionalización del principio de "subsidiariedad", de origen comunitario.

Con relación al sistema normativo que deriva de la nueva arquitectura institucional, la República, a la luz de la revisión constitucional, debe entenderse como un ordenamiento general en el cual el Estado es parte y en el cual las regiones, provincias, ciudades metropolitanas y ayuntamientos son componentes constitutivos con la misma dignidad constitucional. 
En cuanto a este renovado cuadro constitucional, el legislador de revisión constitucional ha readaptado la noción de "interés nacional" (según el art. 117 pfo. $1^{\circ}$ del texto anterior), con la previsión de institutos de garantía dirigidos a proteger bienes constitucionales tales como la unidad jurídica o económica, la tutela de los niveles esenciales de las prestaciones en materia de derechos civiles y sociales, la integridad y la seguridad pública, así como el respeto a las obligaciones comunitarias e internacionales (art. 120 pfo. $2^{\circ}$ ). Estas disposiciones expresan el intento del legislador de revisión de preservar, reajustándolo, el "interés nacional" y de garantizar el principio fundamental de que la República es "una e indivisible" (art. 5 Const.).

La previsión de institutos y medidas de garantía de la unidad nacional se acompaña con la previsión de normas e institutos de garantía del pluralismo institucional y cooperativo, como el principio de la "subsidiariedad" y el de la "leal colaboración", a ser aplicados específicamente en el ejercicio de los poderes sustitutorios (art. 120 Const.). La revisión constitucional (art. 120 pfo. $2^{\circ}$ in fine) confía a la ley ordinaria del Estado la disciplina de las modalidades y sedes donde las exigencias unitarias, de una parte, y las autonómicas, de otra, pueden y deben encontrar la justa confrontación y el necesario equilibrio. De hecho, a esta ley se reserva la fijación de los procedimientos "aptos para garantizar que los poderes sustitutivos se ejercitan dentro del respeto del principio de subsidiariedad y del principio de leal colaboración".

\subsection{Fuentes regionales (estatuto, leyes, reglamentos regionales)}

La nueva arquitectura institucional y normativa de la República de las autonomías antes esbozada ha revisado de manera muy significativa el sistema normativo regional y sus límites, modificando la naturaleza y el rango de las fuentes regionales.

Sobre todo, la potestad estatutaria ha sido significativamente ampliada y valorizada, desde el momento en que la revisión constitucional (Ley constitucional núm. 1/1999) no solo ha suprimido los procedimientos de aprobación parlamentaria anteriormente vigentes, sino que también ha eliminado la obligación de aprobar parlamentariamente la deliberación estatutaria regional por medio de una ley de la República. Esto hace que, en el ejercicio de la potestad estatutaria, el legislador regional tenga como único vínculo "la armonía con la Constitución" (art. 123 Const.).

La eliminación de la fase parlamentaria y la plena integración de los estatutos en el sistema de fuentes regionales (a todos los efectos, ya se trata de una ley regional, aunque atípica,) constituyen una de las más llamativas modificaciones introducidas por la reforma, diferenciando sensiblemente la "posición" de los estatutos regionales respecto 
a las normas de organización previstas en otros ordenamientos (como por ejemplo en el caso de las Comunidades autónomas españolas y los Länder alemanes).

La delicada tarea de "garantía" del principio unitario, que potencialmente podría ser puesto en crisis por opciones excéntricas del estatuyente regional, se confía por una parte al juez constitucional y, por la otra, al cuerpo electoral regional. En consecuencia, la Corte constitucional, a tenor del artículo 123 de la Constitución, deberá controlar las posibles violaciones de la Constitución republicana por parte de los estatutos regionales a instancias del Gobierno de la República (dentro de los treinta días siguientes a su publicación). Igualmente, el estatuto se somete a referéndum popular cuando lo solicite (en los tres meses siguientes a su publicación) una cincuentava parte de los electores de la región o un quinto de los miembros del Consejo regional.

Siendo este el único límite positivizado en el nuevo texto constitucional, el objeto de la disciplina estatutaria se enmarca en las seis materias indicadas por el artículo 123 de la Constitución:

a) los "principios fundamentales de organización y funcionamiento" de la Región;

b) la "iniciativa sobre leyes y disposiciones administrativas regionales";

c) Ios "referéndum sobre leyes y disposiciones administrativas de la región";

d) la "publicación de las leyes y los reglamentos regionales";

e) el "Consejo de las autonomías locales, como órgano de consulta entre las regiones y los entes locales";

f) la "forma de gobierno regional".

\subsubsection{Estatutos y forma de gobierno regional (formas de investidura del Presidente de la Junta regional, relaciones entre Legislativo y Ejecutivo, debilitamiento del papel del Consejo)}

La innovación más significativa de la potestad estatutaria, como ya se ha apuntado, reside en la posibilidad de determinar la forma de gobierno que se considera más idónea al modelo político-organizativo del ordenamiento de cada región. Se trata de una forma de gobierno de compleja definición cuando se refleja en los inevitables impactos que sobre la misma tienen las reglas electorales (sistema de elección), remitidas a la determinación del legislador regional, aunque dentro de los "límites de los principios fundamentales" establecidos por leyes estatales. Esta potestad legislativa regional se extiende a la duración de los órganos electivos así como a los status de inelegibilidad e incompatibilidad de los miembros de los órganos regionales (art. 122 pfo. $1^{\circ}$ Const.). 
La renovada Constitución italiana define en términos bastante claros un modelo de gobierno regional que, sin embargo, solo es válido transitoriamente, es decir, hasta la fecha de entrada en vigor de los nuevos estatutos regionales y la aprobación de la ley básica estatal en materia de sistema electoral regional.

El modelo de relaciones interinstitucionales diseñado por las nuevas disposiciones constitucionales gira en torno a los preceptos contenidos en los artículos 122 pfo. $5^{\circ}$ y 126. pfo. $3^{\circ}$ (ab initio) de la Constitución. En el primero se prevé que "el Presidente de la Junta regional, salvo que el Estatuto regional disponga otra cosa, es elegido por sufragio universal directo", y que "el Presidente electo nombra y revoca a los componentes de la Junta" (cursivas del autor). En el segundo se establece que "la aprobación de la moción de censura sobre el Presidente de la Junta elegido por sufragio universal directo, así como la destitución, el impedimento permanente, la muerte o las dimisiones voluntarias del mismo comportan las dimisiones de la Junta y la disolución del Consejo".

Igualmente importantes son el art, 121 pfo. $4^{\circ}$, que coloca entre las funciones del Presidente -prescindiendo de las modalidades de investidura- la dirección y la responsabilidad de la política de la Junta, en evidente analogía con lo previsto por el artículo 95 de la Constitución respecto al Presidente del Consejo de Ministros; y el art. 121 pfo. $2^{\circ}$ de la Constitución, que ya no prevé la reserva del poder reglamentario a favor del Consejo, que pasa, de este modo, a disposición del Ejecutivo regional (correspondiendo al Estatuto definir su distribución entre Junta y/o Presidente de la Junta).

Estas disposiciones, que actúan con carácter transitorio y que, en el futuro, podrían hacer las veces de directrices para los estatuyentes regionales en la determinación de formas de gobierno de investidura directa de los ejecutivos, diseñan escenarios de neoparlamentarismo o semiparlamentarismo con "gobiernos de legislatura", en los que el jefe del gobierno y la asamblea legislativa reciben su propia legitimación de la misma fuente, a través de la doble y simultánea elección por el cuerpo electoral. Ambos órganos, ligados por un pacto de legislatura, nacen y caen conjuntamente según el conocido aforismo "aut simul stabunt aut simul cadent", de manera que la moción de censura al Presidente y la disolución anticipada del Consejo determina siempre la reelección simultánea de los dos órganos.

Las nuevas disposiciones constitucionales no disponen expresamente, aunque tampoco excluyen, que el Presidente elegido por sufragio universal directo, conjuntamente con los demás miembros por él designados o presumiblemente solo, deba presentarse ante el Consejo para obtener explícitamente su confianza. Cierto es que, en todo caso, entre Consejo y Junta se instaura y se desarrolla una relación de confianza 
(presunta o expresa, implícita o explícita), de la que dan buena cuenta las disposiciones contenidas en los párrafos $2^{\circ}$ y $3^{\circ}$ del renovado artículo 126 de la Constitución, que regulan la moción de censura respecto al Presidente de la Junta regional (y que constituye un vínculo inderogable para el estatuyente regional).

En efecto, mientras el párrafo segundo disciplina tout court la moción de censura al Presidente, ya sea elegido directamente por el cuerpo electoral o de forma indirecta (presumiblemente por el Consejo), el apartado tercero del nuevo artículo 126 de la Constitución regula los efectos que se derivan de la aprobación de la moción de censura en el caso del Presidente elegido por sufragio universal directo: precisamente la dimisión de la Junta y la consiguiente disolución del Consejo.

La disposición contenida en el artículo 126 pfo. $2^{\circ}$ de la Constitución-moción de censura al Presidente de la Junta- reduce el espectro de posibilidades del estatuyente regional en materia de relación entre los órganos de la Región a formas de gobierno parlamentario (aunque fuertemente racionalizadas, en las numerosas implementaciones que este modelo conoce y también en atención al sistema electoral preestablecido).

Además, se mantienen vínculos absolutamente inderogables que imponen cambios de cierta entidad incluso para el estatuyente menos proclive a la innovación: el Presidente de la Junta "dirige la política de la Junta de la que es responsable", con lo que se sanciona su preeminencia funcional tanto respecto a los miembros de la Junta como del Consejo; se modifica la anómala atribución del poder reglamentario a la asamblea legislativa con las consiguientes repercusiones sobre el conjunto de la función legislativa de esta última y, con carácter más general, sobre el sistema de fuentes.

De todos modos, en el sistema diseñado por el nuevo texto constitucional, el Consejo regional pierde el papel de articulación central en el equilibrio de relaciones entre los poderes (al menos respecto a la experiencia de treinta años de formas de gobierno regional, todas ellas inspiradas en la forma parlamentaria), ya se haga una lectura presidencialista de las nuevas disposiciones constitucionales o bien, por el contrario, se exploten lo menos posible las potencialidades mayoritarias.

Así pues, la asamblea legislativa regional: a) pierde su función primaria de determinar/codeterminar la orientación política ${ }^{1}$ y el mo-

1 Por lo tanto, parece haber decaído definitivamente la época de la centralidad de las asambleas legislativas y su consecuencia institucional conocida en la doctrina con la fórmula "gobierno parlamentario de tendencia asamblearia", entre cuyas principales connotaciones seguramente se recordará la pertenencia al órgano legislativo de la competencia de definir (y, en algunos casos, de especificar y de gestionar) la orientación político-administrativa de la Región. En realidad, más allá de las diáfanas disposiciones estatutarias, la dinámica 
nopolio normativo ya que los reglamentos ya no están expresamente reservados a ella; $b$ ) en caso de elección directa del Presidente, pierde también el título de único órgano legitimado directamente por el voto popular y el ius vitae ac necis respecto de la Junta y de su Presidente (salvo disolución de la misma); c) la ausencia de previsión expresa de incompatibilidad entre el cargo de consejero y el de asesor reduce las posibilidades para los miembros del Consejo de acceder al gobierno regional pudiendo ser elegidos asesores externos.

Así pues, resulta evidente que el Consejo regional pierde las atribuciones que le habían sido reconocidas por la Constitución republicana de 1948 y formalmente no adquiere otras nuevas; en cambio, el Presidente y el gobierno de la región reciben toda una serie de facultades de las que carecían en la primera fase estatuyente ${ }^{2}$.

Esto que a simple vista podría parecer una auténtica deminutio capitis de los consejos regionales, podría, no obstante, siempre y cuando fuese debidamente protegida en sede de ejecución estatutaria, recuperar para los mismos aquella centralidad que, en el pasado, era solo presunta. Dicho con otras palabras, si los tres ejes en torno a los cuales deberá girar el Consejo regional -participación, legislación y control- se estructurasen sobre una base racional, podría resultar potenciado su papel institucional.

Lo dicho resulta tanto más verosímil respecto a la definición de un "estatuto regional de las oposiciones" que, a partir de un cierto grado de institucionalización de la función opositora, deberá ser luego modulado según sea la fórmula de gobierno y el sistema electoral por los que se opte. La legislación nacional actual en materia de representación electoral regional permanece en retardo respecto de la actuación de dichos cometidos institucionales, punto obligado de referencia para los consejos empeñados en reescribir los estatutos regionales. Sin embargo, aunque sea en modo diferenciado dentro del panorama de las regiones electorales, no parece que aquella haya asegurado todas las oportunidades conexas con la lógica mayoritaria de fondo prevista en las leyes regionales, lo que se presenta como una de las explicaciones

institucional y la reproducción en el ámbito regional de los rasgos del sistema de partidos nacional, ha desnaturalizado cuando no desvalorizado el papel del Consejo, que a) ha sido reducido a simple órgano de registro del programa político-administrativo de la Región, puesto a punto por las cúpulas de los partidos mayoritarios sin ninguna conexión con la voluntad del cuerpo electoral; b) ha quedado sustancialmente imposibilitado para emplear de manera incisiva los instrumentos tradicionales de control político (preguntas, interpelaciones, mociones) a disposición de los consejeros regionales muy condicionados en sus decisiones por el partido de pertenencia; c) se ha revelado incapaz de desarrollar efectivamente la actividad legislativa a satisfacción de las específicas necesidades de la Región. Cfr. P, Cavaleri, Diritto regionale, Padova, 2003, p. 63.

2 Cfr. BIN, P.: "Reinventare i Consigli?", il Mulino, 3/2000. 
de la incertidumbre de la presente fase de actuación estatutaria (debe recordarse que, a dos años del texto constitucional revisado, todavía ningún estatuto regional ha sido aprobado).

Dada la fluidez y, en cierto sentido, la no entera previsibilidad de las líneas por las cuales se deslizará el contenido "eventual" de los nuevos estatutos, es razonable prever un modelo-tipo de estatuto (constitucional) de la oposición, continente de los principios directivos de la disciplina positiva y del rol y atribuciones correspondientes. La racionalización de la relación fiduciaria (fórmula, composición y programa) es un elemento constitutivo para que la oposición asuma el rol de sujeto institucional de derecho positivo; al delinear la figura de la mayoría de orientación política, fija por lo mismo las premisas para la identificación formal ${ }^{3}$ de la función del grupo (o de los grupos) de oposición. La moción inicial de confianza motivada tendría el fin de enuclear, en el programa, aquella parte sustantiva que justifica la instauración de la relación de confianza y que vincula en igual medida al ejecutivo-mayoría de dirección, en su actuación, y a la oposición, en su control.

No menos relevante es la potenciación de los instrumentos de conocimiento e inspección de los consejos (así como la potenciación de los medios materiales necesarios para la comunicación). De hecho, es propiamente en la carencia de la capacidad de información -que siempre se resuelve en una pérdida de los contactos con la sociedad civil- donde se ha identificado el progresivo decaimiento de las asambleas legislativas como órganos autónomos de decisión y su consecuente subordinación al Ejecutivo. Es innegable que un legislador que obra ex informata conscientia recurre en menor medida a los canales informativos gubernamentales. Evidentemente, dichos instrumentos deben ser ideados para la plena disponibilidad de los grupos de oposición, o al menos prever que a ellos sea confiada su presidencia. Todavía para las funciones públicas debe valer plenamente el principio de la publicidad, a fin de permitir que se conozcan y puedan ser hechas valer las responsabilidades del gobierno.

En fin, con relación al instrumento de investigación por parte del consejo, acude en garantía de la oposición la facultad de activar la investigación cuando esta es reconocida a la minoría y no depende del voto mayoritario de la Asamblea. A la oposición debería ser concedida la facultad de designar una cuota minoritaria garantizada para los nombramientos así como la presidencia de comisiones de diversa relevancia ${ }^{4}$.

3 De hecho, la disposición de la relación de confianza asume el significado de acto constitutivo de la mayoría de dirección y, al mismo tiempo, de oposición política.

4 Como, por lo demás, sucede para los entes locales menores (cfr. art. 44 TUEL, "Garantía de las minorías y control por el consejo"). 


\subsubsection{El referéndum (de confirmación/oposición) en el procedimiento de aprobación de los Estatutos regionales}

Otra cuestión digna de nota se refiere a la rigidez de las fuentes estatutarias y la posibilidad ofrecida a la oposición de relanzar el debate sobre la máxima fuente regional.

La eliminación de la fase parlamentaria constituye, como ya se ha recordado, quizá la más importante (y ciertamente la más vistosa) de las modificaciones introducidas en el art. 123 Const. En efecto, el texto actual dispone que, para la aprobación del nuevo estatuto, es necesario el voto favorable de la mayoría absoluta del Consejo regional, y que tal deliberación debe repetirse dos veces a una distancia de al menos dos meses la una de la otra. La brevedad de la disposición no aclara si la segunda aprobación debe consistir en un voto referido al texto completo, o bien si debe (o puede) procederse a la votación artículo por artículo y, siempre en esta segunda eventualidad, si resulta o no posible proponer enmiendas 5 .

Aun cuando el procedimiento de revisión de los estatutos regionales resulta, en virtud de la naturaleza unicameral del Consejo, globalmente más fácil que el previsto por el art. 138 Const., la solución adoptada por los reglamentos parlamentarios parece ser la más lógica. Parece, por lo tanto, previsible una decisión en el mismo sentido por parte de los Consejos regionales. No obstante, subsiste una diferencia que no puede ser descuidada: mientras el art. 138 Const. -que excluye la posibilidad de recurrir al referéndum en caso que el proyecto de ley constitucional o de reforma constitucional obtenga el voto favorable de los dos tercios de los miembros de las Cámaras- ha permitido modificaciones constitucionales en ausencia de una ley reguladora del referéndum (que no fue aprobada sino hasta 1970), en el caso de los estatutos regionales es siempre posible solicitar el referéndum, con independencia del consenso obtenido en el Consejo y en caso de que lo solicite una cincuentava parte de los electores de la región o un quinto de los componentes del Consejo regional. Por lo tanto, la aprobación de una nueva ley regional de referéndum se configura como un paso necesario para la correcta aprobación, antes de completar dentro del Consejo el iter de los nuevos estatutos y leyes estatutarias. En caso contrario, se podría pensar en el recurso, dentro de los límites de su compatibilidad, a las leyes regionales refrendarias vigentes y a las normas que sobre el referéndum se contienen

Un problema similar se presentó en su tiempo respecto al procedimiento previsto en el art. 138 Const. En aquella ocasión la duda fue resuelta por los reglamentos parlamentarios que, para evitar también que el procedimiento de reforma constitucional se hiciera después gravoso e incierto, establecieron que en la segunda deliberación el voto debía referirse solo al proyecto de ley en su conjunto. 
en los viejos estatutos, las que, en todo caso, siguen en vigor hasta la entrada en vigencia de las nuevas normas.

Con respecto a los estatutos ordinarios, la doctrina ha manifestado alguna perplejidad en orden a la "modesta representatividad de los sujetos legitimados para pedir el referéndum sobre el estatuto" y a la "ausencia de cualquier exigencia de quórum de participación para la válida expresión de la voluntad popular" 6 . Esta facilidad ${ }^{7}$ podría también dar lugar a solicitudes de referéndum por parte de fuerzas extremadamente minoritarias que carecen de representación en el Consejo. De otra parte, no parece posible negar el sentido garantista para la oposición del Consejo, visto que la disposición constitucional permite a un quinto de los componentes del Consejo activar el procedimiento refrendario ${ }^{8}$.

De los trabajos preparatorios de la ley constitucional núm. 1 de 1999 , resulta que el referéndum fue introducido con estas características para desalentar las revisiones estatutarias que podrían producirse al inicio de las legislaturas regionales según la alternancia natural de las mayorías políticas en el seno del Consejo. Compartimos el temor sobre las reformas periódicas, en cuanto la doble aprobación por una mayoría absoluta no es una garantía suficiente ${ }^{9}$, sobre todo a la luz de la particular predilección que muchas fuerzas políticas parecen alimentar hacia los sistemas electorales de tipo mayoritario, lo que por tanto hace vaticinar una opción en este sentido bastante difusa y generalizada.

\subsubsection{La potestad legislativa y reglamentaria de las regiones}

Junto con la potestad estatutaria, ha sido también renovada la potestad legislativa mediante un importante refuerzo de los correspondientes contenidos materiales y de una redefinición de los respectivos límites.

6 En este sentido, U. de Siervo, I nuovi statuti regionali nel sistema delle fonti, en A. Ferrara (a cura di), Verso una fase costituente delle Regioni? - Problemi di interpretazione della legge costituzionale 22 novembre 1999 n. 1, Giuffrè, Milano, 2001, p. 4 y ss.

7 Es necesario anotar que se trata de una facilidad relativa, porque la requerida cincuentava parte de los electores constituye un porcentaje que aproximadamente dobla al necesario, a nivel nacional, para proponer el referéndum a que se refieren los arts. 75 y 138 Const. Con todo, las reducidas dimensiones territoriales pueden constituir indudablemente una notable ventaja para los promotores del referéndum regional.

8 Otra es la problemática inherente al efectivo grado de opción que tiene el electorado, el que en todo caso debe expresarse aceptando o rechazando in toto el proyecto de estatuto.

9 Bajo la vigencia del viejo texto del art. 123 Const., la exigencia de la mayoría absoluta en lugar de una calificada, era considerada por S. BARTOLE (voz Statuti regionali, cit., 549) como un factor que podía "atenuar y reducir la importancia de los estatutos", en cuanto las " 'cartas' revisables y sustituibles por obra de la mayoría que normalmente sostiene a los ejecutivos regionales, evidentemente no pueden pretender para sí la condición de definitivas o la aspiración por la permanencia que es propia de los documentos dotados de más garantías de rigidez". 
En efecto, con respecto al ordenamiento constitucional anterior la reforma ha obrado un nuevo reparto de la competencia legislativa general, generando de esta forma un cambio normativo que afecta al entero sistema de fuentes primarias nacionales, incidiendo problemáticamente sobre el mismo art. 70 Const., conforme al cual la "función legislativa es ejercitada colectivamente por las dos Cámaras". Dicho efecto normativo posee una doble importancia. Primero que todo, por parte del Estado produce la pérdida de la competencia legislativa general y ordinaria, en favor de una ordenación que tiende a equiparar las fuentes legislativas estatales y regionales, lo que lleva a pensar en la posible aplicación de la doctrina sobre "ordenamientos parciales" yuxtapuestos entre sí. Dicha tesis, no obstante, parece menos convincente frente a aquella de la "pluralidad de ordenamientos" (Santi Romano), en cuanto esta no viola el principio unitario del ordenamiento y resulta más coherente con una interpretación lógica y sistemática de la reforma regional a la luz del art. 5 Const.

Otro efecto normativo relevante respecto al régimen anterior, vinculado con las relaciones entre ordenamiento interno y comunitario, se presenta con la constitucionalización del proceso de comunitarización del sistema de fuentes, tanto estatales como regionales, que ahora se someten a los mismos límites del art. 117 , pfo. $1^{\circ}$, Const. Una consecuencia directa de dicha constitucionalización es la redefinición constitucional del papel de las regiones cara a la Unión Europea, con la valorización ya definitiva de la fuente normativa regional en la actuación y ejecución de los actos normativos comunitarios.

Para realizar esta innovación en el ordenamiento de las fuentes, el instrumento utilizado por el legislador de reforma ha sido la inversión del reparto de competencias legislativas entre el Estado y las regiones. En verdad, no solo se trata de una simple inversión del reparto, desde el momento en que se está en presencia de una redistribución de la potestad legislativa general, con la disposición de un sistema de límites abstractamente idénticos para una y otra fuente legislativa.

La nueva repartición regulada en los cuatro primeros párrafos del art. 117 Const. produce una distinción entre tres tipologías de ámbitos materiales de regulación legislativa ${ }^{10}$.

10 "Art. 117.- La potestad legislativa es ejercitada por el Estado y las regiones dentro del respeto por la Constitución, así como de los vínculos derivados del ordenamiento comunitario y de las obligaciones internacionales.

El Estado posee legislación exclusiva en las siguientes materias:

a) política exterior y relaciones internacionales del Estado; relaciones del Estado con la Unión Europea; derecho de asilo y condición jurídica de los ciudadanos no pertenecientes a la Unión Europea;

b) inmigración; 
La primera tipología se encuentra en el párrafo $2^{\circ}$ del art. 117 Const. y consiste en la potestad exclusiva del Estado que se ejercita sobre un ámbito material taxativamente definido (letras "a" a la "s"). La segunda tipología es definida por la misma letra del párrafo $3^{\circ}$ como 'legislación concurrente', conforme al cual la potestad legislativa concurrente corresponde a las regiones, "salvo la determinación de los principios fundamentales, reservada a la legislación del Estado”. La tercera puede ser definida como potestad legislativa exclusiva (o residual)

c) relaciones entre la República y las confesiones religiosas;

d) Defensa y Fuerzas Armadas; seguridad del Estado; armas, municiones y explosivos;

e) moneda, tutela del ahorro y mercados financieros; tutela de la competencia; sistema cambiario; sistema tributario y contable del Estado; compensación de los recursos financieros;

f) órganos del Estado y respectivas leyes electorales; referéndum estatales; elección del Parlamento europeo;

g) ordenación y organización administrativa del Estado y de los entes públicos nacionales;

h) orden público y seguridad; con exclusión de la policía administrativa local;

i) ciudadanía, estado civil y registros civiles;

1) jurisdicción y normas procesales; ordenamiento civil y penal; justicia administrativa;

m) determinación de los niveles esenciales de las prestaciones concernientes a los derechos civiles y sociales que deben ser garantizados sobre todo el territorio nacional;

n) normas generales sobre instrucción;

o) seguridad social;

p) legislación electoral, órganos de gobierno y funciones fundamentales de los Ayuntamientos, Provincias y Ciudades metropolitanas;

q) aduanas, protección de las fronteras nacionales y profilaxis internacional;

r) pesos, medidas y determinación del tiempo; coordinación informativa estadística e informática de los datos de la Administración estatal, regional y local; obras del ingenio;

s) tutela del ambiente, del ecosistema y de los bienes culturales.

Son materia de legislación concurrente aquellas relativas a: relaciones internacionales y con la Unión Europea de las Regiones; comercio exterior; tutela y seguridad del trabajo; instrucción, sin perjuicio de la autonomía de de las instituciones escolares y con exclusión de la educación y de la formación profesional; profesiones; investigación científica y tecnológica y apoyo a la innovación para los sectores productivos; tutela de la salud; alimentación; ordenamiento deportivo; protección civil; gobierno del territorio; puertos y aeropuertos civiles; grandes redes de transporte y de navegación; ordenamiento de las comunicaciones; producción, transporte y distribución nacional de la energía; asistencia social complementaria e integrativa; armonización de los presupuestos públicos y coordinación de las finanzas públicas y del sistema tributario; valorización de los bienes culturales y ambientales y promoción y organización de actividades culturales; cajas de ahorro, cajas rurales, administraciones de crédito de carácter regional; entes de crédito inmobiliario y agrario de carácter regional. En las materias de legislación concurrente corresponde a las regiones la potestad legislativa, salvo la determinación de los principios fundamentales, reservada a la legislación del Estado.

Corresponde a las regiones la potestad legislativa respecto a cualquier materia no reservada expresamente a la legislación del Estado (...).

La potestad reglamentaria corresponde al Estado en las materias de legislación exclusiva, salvo delegación en las regiones. La potestad reglamentaria corresponde a las regiones en cualquier otra materia. Los Ayuntamientos, Provincias y Ciudades metropolitanas tienen potestad reglamentaria para la disciplina de la organización y desarrollo de las funciones a ellos atribuidas (...)". 
de las regiones, valiendo para su ejercicio los mismos límites previstos para la ley estatal.

La ley de reforma constitucional introduce, en fin, otro ámbito material de regulación legislativa regional mediante el recurso, de parte de las regiones que expresan la voluntad, a procedimientos que permitan "formas ulteriores y condiciones particulares de autonomía" en las materias de potestad legislativa concurrente y en ciertas materias bien especificadas de la potestad exclusiva del Estado (art. 116, pfo. $3^{\circ}$, Const.).

La conexión existente entre la equiparación de las fuentes legislativas ordinarias (estatales y regionales) y la constitucionalización de la comunitarización de las mismas fuentes constituye una de las más importantes innovaciones con relación al nuevo rol de las regiones de cara a la actuación del Derecho comunitario.

Luego de lo dicho sobre el sistema de fuentes y de distribución de la potestad legislativa, es necesario al menos referirse a las formas de disciplina constitucional sobre la potestad reglamentaria. El nuevo reparto normativo redimensiona la potestad reglamentaria estatal, limitándola (en el sentido del art. 117 , pfo. $6^{\circ}$, Const.) exclusivamente a las materias de competencia exclusiva y disponiendo una facultad de delegación a las regiones sobre las mismas materias.

Incidiendo sobre materias reservadas a la ley estatal, la competencia reglamentaria del Estado presenta complejas cuestiones de interpretación y de actuación. Esto se produce tanto respecto a la relación entre fuentes relacionadas con materias transversales (comunitarias, estatales y regionales, por ejemplo, en materia de medio ambiente, ecosistema, normas generales sobre educación, tutela de la competencia, etc.), como respecto a la permanencia misma de infraestructura administrativa estatal en sectores de competencia regional (concurrente y residual). En este sentido, es de preguntarse si deberá prevalecer el criterio de jerarquía o el de competencia en la resolución de las eventuales antinomias entre reglamentos estatales y reglamentos regionales. Esto también en consideración a la nueva distribución de competencia reglamentaria a cargo de los ejecutivos regionales, que ha determinado una valorización de dicho instrumento normativo.

Sobre la materia de qua parece admisible aquella construcción doctrinal que propone como hipótesis la necesidad de reservar a los consejos regionales el ámbito reglamentario relativo a los espacios materiales cubiertos por la reserva absoluta de ley.

Por último, con relación a los controles preventivos se presenta un problema de orden general con la asimetría en el ejercicio de la potestad reglamentaria (aunque sea diferenciada) de las regiones y entes autónomos con respecto a la potestad reglamentaria gubernativa, que permanece sujeta a los controles de legitimidad de la Ley 
núm. 400/1988. Mientras, para los actos reglamentarios del gobierno continúan aplicándose las disposiciones constitucionales y legislativas relativas a la tutela del principio de legalidad y de la reserva de ley, y contrariamente el nuevo texto constitucional ha dejado sin cobertura la materia de los controles sobre los reglamentos regionales.

\subsubsection{Los límites de la potestad legislativa regional (en particular, en materia de contenidos esenciales de los derechos civiles $y$ sociales)}

Como ya se ha dicho, con relación al renovado cuadro constitucional que articula la República, el legislador de revisión constitucional reformuló implícitamente la noción misma de "interés nacional" (art. 111 , pfo. $1^{\circ}$, del texto constitucional anterior), disponiendo institutos de garantía para la protección de bienes constitucionales tales como la unidad jurídica o económica, la tutela de los niveles esenciales de las prestaciones en materia de derechos civiles y sociales, la integridad y la seguridad pública, así como el respeto de las obligaciones de naturaleza comunitaria e internacional (art. 120, pfo. $2^{\circ}$, Const.). Tales disposiciones, de hecho, explicitan el intento del legislador de revisión por preservar el interés nacional, reconfigurándolo, y de garantizar el principio fundamental según el cual la República es "una e indivisible" (art. 5 Const.).

Con tal propósito, en el reparto de competencias el renovado texto constitucional ha asignado como competencia de la legislación exclusiva del Estado "la determinación de los niveles esenciales de las prestaciones concernientes a los derechos civiles y sociales". Del mismo modo, ha previsto que las materias de legislación concurrente (art. 117, pfo. $3^{\circ}$, Const.) reconozcan el límite de los principios fundamentales, igualmente reservados a la legislación del Estado. Según un criterio de interpretación lógico-sistemática, el mismo límite se extiende a la potestad legislativa exclusiva o "residual" de las regiones (art. 117, pfo. $4^{\circ}$, Const.), descartándose el ejercicio de competencias regionales, en el sentido del párrafo $4^{\circ}$, que no apliquen: a) los límites del art. 117, pfo. $1^{\circ}$ (respeto a la Constitución y a los vínculos derivados del ordenamiento comunitario y de las obligaciones internacionales), donde por "respeto a la Constitución" debe entenderse, sobre la base de una interpretación sistemática y por principios, el respeto de todos los principios fundamentales y de las disposiciones constitucionales en materia de derechos fundamentales; b) los límites a la legislación regional fijados por las exigencias de unidad jurídica y política y, por tanto, también de los "niveles esenciales de las prestaciones concernientes a los derechos civiles y sociales", los cuales por dictado de la Constitución, "deben ser garantizados sobre todo el territorio nacional". 
A diferencia del anterior ordenamiento, el revisado Tít. V Const. dispone una relación explícita y directa entre el "nuevo" regionalismo italiano y las nuevas técnicas de regulación de los derechos sociales y civiles. Respecto al texto del precedente art. 117 Const., la nueva formulación ha previsto (y consiente) ámbitos competenciales en materias que poseen repercusiones (no exentas de problematicidad interpretativa) sobre los derechos fundamentales, sean sociales o civiles. La cantidad y la calidad de la nueva distribución de competencias es plenamente comparable a la que opera en los sistemas federales (y hasta confederales, como el helvético), diferenciándose solamente por las técnicas institucionales de distribución y la respectiva legislación de ejecución e integración.

Al asignar a la legislación exclusiva del Estado la "materia" -que no pocas veces constituye una función, como lo ha recordado la Corte Constitucional en dos importantes sentencias (n. 282/2002 y n. 407/2002) - relativa a la "determinación de los niveles esenciales de las prestaciones concernientes a los derechos civiles y sociales", la nueva disposición constitucional se propone explícitamente asegurar la garantía del principio de igualdad frente a la ley "sobre todo el territorio nacional", que debe entenderse aquí, más que nada, como igualdad frente a la Constitución.

A saber, el legislador de revisión se mueve dentro de un cuadro teórico-constitucional donde se asume como definitivamente superado el modelo (jacobino) de uniformismo y centralismo, al que corresponde en la práctica una legislación regional sustancialmente homóloga (la llamada legislación "fotocopia", no siempre en sentido metafórico).

Respecto a un horizonte teleológico semejante, se presentaban como posibles la eventual lesión del principio de igualdad de los ciudadanos (igualdad interpersonal), incluso al interior de cada región, y sobre todo la desigualdad con relación al lugar de residencia (igualdad interterritorial). Mientras con respecto a la primera situación parecía suficiente la disposición del art. 3 , pfo. $1^{\circ}$, Const., podían quedar sin cobertura constitucional las eventuales desigualdades interterritoriales, en consideración a la realidad sociopolítica del país, todavía caracterizada por la persistente "cuestión meridional" y por una fuerte diferencia socioeconómica entre el norte y el sur del país. Es sobre todo frente a tal posible desigualdad, que la disposición de la letra $\mathrm{m}$ ) constituye una garantía del derecho de "ciudadanía social", además de la previsión de un límite ulterior, constituido por los principios fundamentales reservados a la legislación del Estado.

Con todo, si el legislador de revisión constitucional ha puesto remedio -con las disposiciones de la letra $\mathrm{m}$ ) del art. 117 , pfo. $2^{\circ}$, Const.- a las posibles lesiones del principio de igualdad interpersonal e interterritorial (también en razón de las previsiones del reformado art. 116 Const.), debe subrayarse cómo funciona en la misma óptica 
(de garantía de la "ciudadanía social") el entero sistema de principios fundamentales ( $\mathrm{y}$ entre estos, en particular, el principio personalista y solidario del art. 2 Const.) y de disposiciones constitucionales en materia de derechos fundamentales, en cuanto patrimonio constitucional indisponible para la misma revisión constitucional. En efecto, en la actuación del principio de solidaridad, corresponde a la "República" (entendida como el conjunto de todos los poderes públicos, nacionales y territoriales) hacer valer, a título de solidaridad y de cohesión social, todas aquellas garantías que contribuyen, con el principio de igualdad sustancial, a superar las desigualdades que se originan en el sistema económico y social, removiendo los desequilibrios y favoreciendo el ejercicio efectivo de los derechos de la persona.

Al legislador (estatal y regional) y al restante sistema autonómico de la República, en el ejercicio de los poderes normativos de que son titulares y dentro del respeto al principio de subsidiariedad y de colaboración leal, les corresponde asegurar la tutela de la unidad jurídica y económica, y en particular la tutela de los niveles esenciales de las prestaciones concernientes a los derechos civiles y sociales, prescindiendo de los confines territoriales de los gobiernos locales (art. 120, pfo. final, Const.). En tal sentido, y en las hipótesis normativas fijadas en la Constitución (art. 120, pfo. $2^{\circ}$ ), el Gobierno estatal puede sustituir a los órganos de las regiones, ciudades metropolitanas, provincias y ayuntamientos, dentro del respeto por los procedimientos legales relativos a tal control sustitutivo.

Si bien la disposición del art. 117 Const., pfo. $2^{\circ}$, letra m), podía no parecer en principio estrictamente necesaria a los fines de tutela de los derechos constitucionales fundamentales - de hecho, en el renovado ordenamiento regional y local encuentran, como ya se ha recordado, plena aplicación los principios fundamentales destinados a la tutela de la unidad e indivisibilidad de la República y de las respectivas garantías constitucionales - se concluye que tal disposición encuentra su motivación en la exigencia de explicitar que el cuadro constitucional de los principios fundamentales no ha registrado modificaciones sustanciales.

En tal marco, el ordenamiento constitucional registra los únicos límites -ya plenamente constitucionalizados en el art. 117 , pfo. $1^{\circ}$, Const.- fijados para el respeto de la Constitución y de los vínculos derivados del ordenamiento comunitario y de las obligaciones internacionales. Esta última es una norma que explicita -de forma menos precaria de cuanto no fuera permitido por la ambigüedad de las formulas del art. $10 \mathrm{y}$, sobre todo, del art. 11 Const.- el vínculo de la confirmación por las obligaciones establecidas por el derecho internacional y el derecho comunitario. Se trata, sobre todo en este último caso, de un Derecho nacido para asegurar la unidad del mercado en el ámbito europeo y, con dicho propósito, la libertad de circulación de mercancías, personas 
y capitales, y que a continuación se ha abierto al reconocimiento de los principios de libertad, democracia, respeto a los derechos del hombre y a las libertades fundamentales, y Estado de Derecho, en tanto principios y tradiciones constitucionales comunes a los Estados miembros (art. 6 TUE).

Aunque muy brevemente, puede ahora destacarse cómo las cuestiones interpretativas que propone el art. 117 , pfo. $2^{\circ}$, Const. se refieren no tanto, como ya se ha dicho, a la ratio de la disposición citada como sobre todo a los respectivos contenidos y, en consecuencia, a la tipología de los derechos civiles y sociales (categoría por primera vez ingresada en el léxico constitucional) a ser garantizados sobre todo el territorio nacional en los "niveles esenciales" de las correspondientes prestaciones.

La legislación concurrente en las nuevas materias en las que resulta competente-implementadas significativamente respecto al anterior art. 117 Const. - y aquella atribuida en forma residual, deberán ejercitarse (con las posibles diferencias de estatus de las regiones) sin poner en cuestión el estatuto de la ciudadanía, la que deberá permanecer como "nacional" y "social". De esta forma se aseguran, por una parte, los niveles esenciales de las prestaciones en materia de derechos civiles y sociales, y por otra parte, la inderogabilidad de los deberes de solidaridad política, económica y social entre los sujetos y las diversas zonas del país.

Al fundarse sobre una separación "innatural" entre materias (y potestades/funciones), por una parte, e intereses, por otra, el reparto obrado por el legislador de revisión constitucional aparece complejo, confuso e incluso (quizá) "ingenuo" en su "pretensión" de detener el movimiento irreversible de los intereses sobre la base del ordenamiento. Otra vez serán los esfuerzos del intérprete y del juez de las leyes los llamados a (deber) componer, dentro de un cuadro de compatibilidades constitucionales, las opciones diferenciadas (en el tiempo y en el espacio) del legislador estatal y del regional. Resultará fundamental, a los fines de tal recomposición (doctrinal y jurisprudencial), la previsión de la letra $\mathrm{m}$ ) del art. 117 , pfo. $2^{\circ}$, Const., desde el momento en que la "línea divisoria entre las competencias, tan sutil como el filo de una navaja... (es) representada por (y reconstruyéndose enteramente en torno a) el carácter esencial de las prestaciones" (A. Ruggieri).

Sin embargo, en materia de derechos (civiles y sociales) la interpretación de los contenidos materiales del art. 117 Const. se remite a una mirada de conjunto, a lecturas fuertemente diferenciadas entre sí, según prevalezca o no una dirección cultural e institucional de discontinuidad respecto a la disciplina de la materia vigente en el ordenamiento anterior.

La cuestión nace de la individualización de los límites a los cuales se encuentra sujeta la potestad legislativa regional concurrente -a cuya 
solución dispone explícitamente el legislador de revisión constitucional cuando limita tal potestad a la determinación de los "principios fundamentales" con leyes estatales- y particularmente de la cuestión acerca de si resulta o no extensible tal régimen de vinculaciones a la misma potestad legislativa residual o exclusiva de las regiones.

A tal fin, parece totalmente convincente aquella tendencia doctrinal que invoca -como título de legitimación de la potestad legislativa estatal que justifica la eventual intervención- la finalidad garantizadora de la tutela del bien constitucional de la unidad, y en particular la protección de las prestaciones relativas a los derechos civiles y sociales prescindiendo de los límites territoriales de los gobiernos locales, sin perjuicio de la intermediación de los principios fundamentales o de una disciplina específica. En conclusión, estamos en presencia de un nuevo cuadro constitucional y legislativo, donde con relación a los derechos (civiles y sociales) se abre para las regiones un nuevo ámbito regulador y de garantías, y al mismo tiempo se confirma para el Estado la competencia para intervenir en dicha disciplina regional, sea mediante el establecimiento de los principios fundamentales de la materia, sea a través de reglas legislativas.

Aun cuando la reforma constitucional podía aparecer funcionando bajo el signo de la continuidad sustancial, el ángulo de observación de los derechos civiles y sociales abre un cuadro dispositivo autonomista valorizado en el ámbito de sus poderes y, entre estos -diversamente de cuanto estaba previsto en el ordenamiento anterior- de ámbitos normativos que se extienden a la misma materia de los derechos civiles y sociales. No obstante, tales poderes reconocen en su ejercicio un límite negativo, en el sentido de que las regiones -sea en el ejercicio de la potestad legislativa concurrente o en aquella residual/exclusiva- deben ajustarse a las vinculaciones impuestas por los principios fundamentales y las reglas legislativas estatales establecidas como garantía de los bienes fundamentales a que se refiere la letra m) y el art. 120, pfo. $2^{\circ}$, Const.

Con todo, es necesario decir que en esta materia se han propuesto interpretaciones contrapuestas entre sí. En una primera opción (sobre la cual volveremos para tomar distancia), la esencialidad a que se refiere la letra $\mathrm{m}$ ) es interpretada como un "contenido mínimo esencial" (I. Massa Pinto), recurriendo a la jurisprudencia de la Corte Constitucional que, según tal opinión, obtendría la respectiva fórmula por vía interpretativa, en el momento en que el juez de las leyes está llamado a juzgar la "razonabilidad" de las opciones políticas que la discrecionalidad del legislador implica. Corroboraría tal lectura el mismo enfoque comparatista y comunitario, en el cual se encuentra, como cláusula general, aquella del "contenido mínimo esencial" de los derechos fundamentales. Es el caso, por ejemplo, del art. 19 de la Ley Fundamental de Bonn, 
del art. 53.1 de la Constitución española, del art. 18.3 de la Constitución portuguesa o del art. 53.1 de la Carta europea de los derechos fundamentales.

Más fundada y convincente parece otra lectura que, con una interpretación lógico-sintáctica y sistemática del texto constitucional reformado, coloca junto a las disposiciones de la letra $\mathrm{m}$ ) las del art. 119 , pfo. $5^{\circ}, y$ del art. 120 , pfo. $2^{\circ}$, Const. y, en línea con las más calificadas interpretaciones de la Constitución, subraya la irreductibilidad (incluso semántica) del término "esencial" con el término "mínimo". En esta óptica, el término "esencial" es más bien leído como una fórmula relacional. Como se observa acertadamente, "el concepto de prestación esencial es un concepto relativo, es decir, depende de la persona a la cual se dirige la prestación y depende también del tipo de situación en la cual se encuentra" (M. Luciani). Una confirmación de dicha interpretación puede encontrarse en la consideración según la cual la naturaleza de los "niveles esenciales de las prestaciones" no se refiere solamente a los derechos sociales sino que también incluye a los civiles que según la doctrina consolidada -bien que derechos que "cuestan" no admiten una reducción o degradación de sus respectivos contenidos. En cuanto derechos subjetivos relativos al status libertatis, ellos se califican como derecho objetivo y, por lo tanto, imponen obligaciones y prohibiciones a los poderes públicos con el objeto de asegurar la plenitud de la situación jurídica protegida y la respectiva justiciabilidad (en la forma clásica de la tutela resarcitoria).

Por otra parte, la disposición constitucional del art. 120, pfo. $2^{\circ}$, reafirma una lectura de la "esencialidad" no reducida al mínimo, al hacerse cargo de las deficiencias organizativo-administrativas de tales prestaciones -erogadas no solo por el Estado, sino también por las regiones y por los otros entes autónomos de la República-, y al especificar la tutela de los "niveles esenciales" de las prestaciones relativas a los derechos civiles y sociales sobre todo el territorio nacional. Con esto confirma una posible y convincente lectura de un no desaparecido interés nacional, al considerarse como un verdadero y propio título habilitante, para intervenir sobre todas las materias (redistribuidas en el sentido del art. 117 Const.). Ciertamente, como ya se ha recordado, que no estamos en presencia de la misma noción de "interés nacional" a que se refería el ordenamiento constitucional anterior a la reforma, en cuanto el interés "nacional" del que ahora se trata es el interés tipificado en sus hipótesis concretas, aun cuando estas últimas sean merecedoras de interpretación.

Empero, y como confirmación de las orientaciones recién referidas, resulta en el fondo que la clave de bóveda de este difícil equilibrio reside en el valor de la solidaridad y en los instrumentos del equilibrio presupuestario. 
De esta manera, podemos concluir destacando cómo el riesgo de un "deslizamiento hacia abajo" de los contenidos de la nueva disciplina de las prestaciones esenciales en materia de derechos civiles y sociales, y de un límite difícil de oponer al "arbitrio de las mayorías", pueden y deben ser superados. Para ello habrá de recurrirse a las más avanzadas (y convincentes) interpretaciones de la Constitución, magis ut valeat, o a una jurisprudencia constitucional que, a través de las técnicas jurisdiccionales hasta ahora utilizadas, ha sabido dar prueba de equilibrio (y también de prudencia) en la ponderación de los bienes constitucionales involucrados cada vez en el proceso constitucional, comprendiendo la necesaria gradualidad en la actuación legislativa o el respeto por la discrecionalidad del legislador.

De otra parte, no podría ser de otro modo en un Estado que se caracteriza por una Constitución rígida, en la cual la materia de "contenidos esenciales" se conecta de un modo estrecho e indisoluble con aquella propia de los principios supremos y de los derechos inviolables del hombre. Así lo asumen concordemente la jurisprudencia (especialmente la sentencia de la Corte Const. núm. 1146/1988) y la doctrina constitucional, cuando sostienen la sustracción de la referida disciplina constitucional al mismo poder de revisión de la Constitución. La cuestión así presentada, aunque en sus términos fundamentales, no presenta problemas interpretativos al referirse al "contenido esencial" de los derechos de libertad, que se califican necesariamente como "derechos entre derechos" y por lo tanto no como conceptos absolutos. Aquel no puede ser determinado a priori sino solo ex post, en razón de un escrutinio constitucional de la irracionalidad de las disposiciones legislativas eventualmente limitativas. Por el contrario, la cuestión permanece abierta con relación a la delicada y compleja determinación del "contenido esencial" de los derechos sociales, para cuya existencia jurídica se requiere, como condición necesaria, de la interpositio legislatoris y de la adopción de medidas organizativas para su respectiva implementación.

Aun dentro del respeto por el principio de gradualidad y del equilibrio con otros bienes o intereses constitucionales, es razonable preguntarse si la garantía constitucional considera el "contenido esencial" de los derechos con respecto a la mera existencia de los mismos, o si bien, al contrario, si dicha tutela no deba extenderse también al quantum de los mismos. El escrutinio de la copiosa jurisprudencia constitucional lleva a inclinarse por la primera solución, limitándose dicho control jurisdiccional a no poner en cuestión la necesaria discrecionalidad del legislador para dar actuación a los principios y derechos fundamentales. No obstante, es cierto que dicha discrecionalidad reconoce como límite la "reserva de lo razonable y de lo posible" (A. Baldasarre), por lo que, como observa la misma Corte, "la determinación legislativa de lo que 
debe ser la indemnización equitativa (y nosotros podemos entender como contenido esencial del derecho) podría ser objeto de censura en sede de juicio de legitimidad constitucional solo en cuanto fuera tan exigua como para privar de sustancia, reduciéndolo a un nombre privado de contenido concreto, el derecho a la indemnización misma" (sentencia Corte Constitucional núm. 27/1998). Se puede sacar la conclusión, que por la orientación desarrollada en este párrafo no invita al entusiasmo, de que la misma jurisprudencia constitucional en materia de contenido esencial de los derechos sociales no parece asegurar siempre una tutela más definida y estable de cuanto no logre el legislador hacer con sus opciones políticas (en un tiempo solo estatal, hoy también regional).

Sin embargo, retomando el razonamiento desarrollado precedentemente, si la Constitución es, como sabemos, un conjunto de valores articulados y positivados en principios fundamentales y disposiciones de protección, es a una lectura o interpretación necesariamente "según principios" (y no solo "por reglas") que el intérprete (y a fortiori el juez de las leyes) debe recurrir si no quiere desatender el mandato constitucional al cual el mismo es llamado. Esto, dentro del hacer viviente un patrimonio constitucional de garantías que, aun esparciéndose en una heterogeneidad de disposiciones, solo mediante una interpretación sistemática y evolutiva puede conocer su plena reconstrucción y, con ella, la correspondiente vigencia; en una palabra, la "Constitución viviente" (G. Zagrebelsky).

Como se puede advertir, dicha orientación entrega al intérprete (doctrina y juez constitucional) un verdadero rol de garante de los contenidos esenciales de los derechos fundamentales, entendidos como el "producto de un cúmulo de actitudes prácticas con respecto a criterios de conducta" (G. Zagrebelsky) y no como abstractas categorías metafísicas. Esto es, como resultado de una lectura estratificada y consolidada de la Constitución, colocando de tal modo un límite infranqueable en el proceso de identificación del "contenido esencial" de los derechos. Un límite que, dentro del respeto por los principios y disposiciones inviolables (y por lo tanto inderogables), debe valer tanto para el legislador (estatal o regional) en su discrecionalidad política, como para el juez constitucional en la ponderación según la razonabilidad.

\subsubsection{Perspectivas (ulteriores y problemáticas) de la reforma de la reforma: la denominada devolution a la italiana}

La revisión del Título $\mathrm{V}$ no resulta completa si se tiene en cuenta que el Gobierno ha aprobado dos sucesivos proyectos de ulterior revisión del Tít. V Const. El primero de dichos proyectos, al cual se limita esta reflexión (no apareciendo todavía clara ni definitiva la voluntad de la mayoría parlamentaria por confirmar las líneas proyectivas de una ul- 
terior reforma en relación a la, así llamada, devolution propuesta por el Ministro Bossi), consiste en la integración dentro del art. 117 Const. de una nueva disposición atributiva de competencias exclusivas de las regiones (en materia de sanidad, instrucción y policía local) ${ }^{11}$.

Una nueva y breve premisa parece útil en el análisis que vamos a desarrollar. Aun cuando en la doctrina publicista corriente en Italia se tiende a definir el proceso de reformas con el término de federalismo, es necesario replicar que el regionalismo italiano posterior a la reforma no es de tipo federal, en cuanto carece de los perfiles estructurales y de legitimación (soberanía de los Estados miembros) de este último. Por lo tanto, desde un punto de vista técnico formal, el modelo de Estado diseñado por los revisores de la Constitución no es federal, y ni en verdad así se autodefine. Para poder hablar verdaderamente de federalismo, deberíamos estar en presencia de otros tantos Estados soberanos (Estados miembros, Länder) y de una segunda Cámara con funciones de representación institucional de las regiones/Estados y de participación de estos mismos en la revisión constitucional. Por el contrario, el modelo recogido presta atención a un regionalismo fuerte, particularmente valorizado en las competencias concurrentes de las regiones, con la previsión de un criterio de residualidad para la competencia legislativa regional, así como de una amplia potestad normativa y estatutaria concerniente a la organización política del ente (que excluye, como se ha dicho, la sola forma presidencial en presencia de la previsión de la moción de censura al Ejecutivo por parte del Legislativo, criterio que identifica estructuralmente las formas de gobierno parlamentarias).

En dicho cuadro normativo general, una parte de la doctrina italiana se interroga acerca de las relaciones entre la nueva descentralización territorial de los poderes y el principio de igualdad de los ciudadanos (entendida, en particular, como igualdad interpersonal e interterritorial). En Italia esto resulta relevante, particularmente con relación a una no resuelta cuestión meridional y, más en general, a un regionalismo caracterizado por regiones (económica y fiscalmente) débiles, las regiones del sur, y regiones ricas, las regiones del centro-norte del país. Por otra parte, es

11 Art. 1 (modificación del artículo 117 de la Constitución".- 1. Después del párrafo cuarto del artículo 117 de la Constitución, se inserta el siguiente: "Las regiones ejercitan la competencia legislativa exclusiva para las siguientes materias:
a) asistencia y organización sanitaria;
b) organización escolar, gestión de los institutos escolares y de formación, sin perjuicio de
la autonomía de las instituciones escolares;
c) definición de aquella parte de los programas escolares y formativos de interés específico de la Región;
d) policía local". 
necesario recordar que en el texto de revisión de la Constitución desaparece una disposición prevista en el anterior artículo 19 , pfo. $3^{\circ}$, Const., dirigida particularmente a "valorizar el Mezzogiorno y las Islas" a través de contribuciones especiales fijadas por medio de leyes del Estado. A cambio, el texto constitucional revisado (art. 119, pfo. $5^{\circ}$, Const.) continúa previendo "intervenciones especiales en favor de determinados ayuntamientos, provincias, ciudades metropolitanas y regiones" para favorecer finalidades de desarrollo económico, de cohesión y de solidaridad social. Por lo tanto, el significado de la reforma aparece como principalmente "simbólico"; desaparece el Mezzogiorno, asumiéndose la necesidad de una intervención pública de cara a una genérica disposición constitucional en la cual, la anteriormente clara semiología de los términos "Mezziogiorno e Islas", se sustituye por un anodino y anónimo "en favor de determinados ayuntamientos, provincias, ciudades metropolitanas y regiones". Sin embargo, si ya el texto vigente omite, ut sic, "Mezzogiorno e Islas", la cuestión aparece más problemática para quienes nos interrogamos sobre los efectos aplicativos de la disposición de revisión constitucional prevista en el proyecto de reforma denominado "Bossi".

La devolution del proyecto de ley de revisión constitucional del 2002, tomada como una etapa ulterior en el camino hacia un federalismo auténtico (por la componente "liguista"* de la actual mayoría parlamentaria), se inserta sobre niveles decididamente distintos respecto del proceso devolutivo recientemente desarrollado en Gran Bretaña. Agregando un párrafo posterior al art. 117 Const., el proyecto confiere a las regiones, por vía constitucional y no legal, competencias legislativas sobre algunas materias que sus promotores consideran fundamentales para las relaciones entre los poderes públicos y los ciudadanos. De esta manera, la transformación de la competencia legislativa regional de concurrente a exclusiva produce el efecto de suprimir, en las materias indicadas en el pfo. $4^{\circ}$ del art. 117 Const., el límite de los principios fundamentales establecidos por las leyes del Estado, límite que todavía hoy continúa, como se ha dicho, presidiendo el ejercicio de la potestad legislativa regional en las materias en cuestión.

Por lo tanto, si el legislador regional adquiere con la devolution competencias legislativas desvinculadas del límite relativo a los principios fundamentales, es por otra parte importante subrayar que tal adquisición se encuentra subordinada a una acción preventiva de "activación" que debe ser promovida por las regiones. Se verifica un proceso "ascendente", un proceso que parte desde abajo y que, en cuanto tal, es profundamente distinto a la devolution británica, en la cual las competencias son transferidas desde el centro hacia la periferia. En suma, la devolution

* Perteneciente al partido político denominado Liga Norte (N. de los T.). 
"a la italiana", que emerge de las intervenciones en el Parlamento del Ministro Bossi y de la relación que acompaña al proyecto de ley, presenta rasgos propios y características específicas que aparecen todavía más evidentes si se observa el contexto político institucional en el cual se inscribe el proyecto de reforma. En este contexto, la Constitución deja de ser vista y vivida como la "Constitución de todos". Por un lado, su revisión se transforma en terreno de conflicto político entre las fuerzas de gobierno y oposición, y por otro, se realiza en la gran parte de los casos a través de mayorías extremadamente arriesgadas.

En efecto, el proyecto de devolución actualmente en discusión, además de ser presentado en contraposición con la reforma del Título $\mathrm{V}$ (realizada por la legislatura precedente) -con la intención de realizar el federalismo desatendido por la ley constitucional núm. 3/2001-, no solo no es apoyado por el consenso del mundo de las autonomías locales, sino que ni siquiera cuenta con el de las autonomías regionales, hecha la excepción, aunque con algunas reservas, de las regiones con mayoría política de centroderecha. Más allá de las reflexiones sobre las nuevas lógicas que subyacen a la revisión de la Constitución -bajo el perfil del carácter de autoatribución de competencias, así como del carácter exclusivo de dichas competencias y de las materias concernidas- el proyecto de reforma en cuestión lleva a preguntarse si acaso sea, para utilizar una eficaz expresión de L. Vandelli, "una pompa de jabón o bien una bomba que amenaza con hacer estallar la forma de Estado italiana" delineada por la Carta Fundamental de la República ${ }^{12}$.

Analizando el proyecto de ley sobre la devolution a partir del carácter de autoatribución de las competencias ("Las regiones ejercitan la competencia legislativa exclusiva para las siguientes materias..."), no puede dejar de destacarse cómo la autoatribución o la ausencia de la misma por parte de las regiones respecto a la competencia exclusiva sobre algunas materias, también determina, junto con su grado de autonomía, un proceso de diferenciación entre las regiones que, según los promotores de este proyecto, es homologable al caso español. En realidad, la devolution italiana se encuentra lejos de proponer un reparto de competencias entre Estado y comunidades autónomas como el desarrollado en España, y configura más bien una experiencia totalmente nueva en el panorama del constitucionalismo contemporáneo. A diferencia de lo que sucede en España, donde la desconstitucionalización del reparto de competencias ha remitido la regulación de algunas materias a los estatutos de autonomía, es decir a las leyes orgánicas aprobadas por el Parlamento, en la devolution italiana falta un punto de encuentro entre la voluntad de la región y la del Estado.

12 Vandelli, L.: Devolution ed altre storie, Bologna, 2002. 
Si es claro que no se encuentran en el Derecho comparado otras experiencias de autoatribución de competencias como la prevista en el proyecto sobre la devolution, no resulta igualmente claro el exacto alcance del proceso de ejecución al que las regiones se encuentran llamadas a realizar. En otros términos, se nos interroga si el contenido de la propuesta prevé que las regiones "deban" o solo "puedan" ejercitar la competencia legislativa exclusiva. Es evidente que, según la interpretación que se dé, resultarán impulsos hacia la uniformidad o hacia la diferenciación.

La activación de las competencias por parte de las regiones, sea ella facultativa u obligatoria, se revela estrictamente relacionada con el mérito atribuido a la "exclusividad" de las competencias que las regiones adquirirán. Si de hecho tal exclusividad desvincula al legislador regional de los principios fundamentales sobre la materia, por otra parte continúa sujetándolo a los vínculos derivados del ordenamiento comunitario, de las obligaciones internacionales $y$, obviamente, del respeto a la Constitución. Este último límite no se agota en el respeto de su primera parte y se vincula con el pfo. $2^{\circ}$ del art. 117 Const., que reserva al Estado las competencias legislativas exclusivas en toda una serie de materias y ámbitos que, como lo ha destacado la misma Corte Constitucional, van desde la "determinación de los niveles esenciales de las prestaciones concernientes a los derechos civiles y sociales" y del ordenamiento civil y penal, hasta la tutela del ambiente y de la competencia, interfiriendo con las competencias regionales y determinando en consecuencia superposiciones de fuentes normativas que imponen enlaces y procedimientos.

En suma, es evidente que la puesta en ejercicio de las competencias legislativas de tipo exclusivo por parte de las regiones libera a las mismas, única y exclusivamente, del límite relativo a los principios fundamentales sobre la materia, con la consecuencia de que la competencia legislativa regional ex art. 117 , pfo. $4^{\circ}$, Const., resulta del todo parecida a aquella que se deriva del párrafo $2^{\circ}$ del art. 117 Const. En esta hipótesis, la devolution a la italiana se resolvería en una pompa de jabón, "pompa de jabón" destinada, no obstante, a transformarse en una "bomba" en el caso de que la competencia legislativa exclusiva de las regiones en las materias a que se refiere el párrafo $4^{\circ}$ se entienda como un tertium genus que se ubica al lado de las competencias concurrentes y residuales. En este caso es evidente que los límites transversales del párrafo $2^{\circ}$ del art. 117 Const. están destinados a sucumbir, con los consiguientes efectos destructivos sobre la forma de Estado delineada por la Constitución de la República.

También son numerosos los aspectos de reflexión y problematicidad en la vertiente relativa a las materias implicadas en la devolution (asistencia y organización sanitaria; organización escolar, gestión de los institutos escolares y de formación, sin perjuicio de la autonomía de las instituciones escolares; definición de aquella parte de los programas 
escolares y formativos de interés específico de la Región; policía local). Más allá de las cuestiones interpretativas, el dato más significativo de la devolution a la italiana se ubica en la relación entre este proyecto de reforma constitucional y el art. 119 Const., cuyo párrafo $4^{\circ}$ establece que "los recursos que derivan de las fuentes a que se refieren los párrafos precedentes permiten a los ayuntamientos, provincias, ciudades metropolitanas y regiones financiar integralmente las funciones públicas a ellas atribuidas". En esta relación es posible identificar el verdadero elemento de asimetría ínsito en el diseño devolutivo en cuestión, visto que no todas las regiones dispondrán de los recursos para poner en ejercicio tales competencias, en cuanto el párrafo $3^{\circ}$ del art. 119 Const. no ha previsto la intervención de fondos estatales. Así, si algunas regiones ejercitan aquellas competencias teniendo los recursos para hacerlo, las otras que carecen de estos continuarán permaneciendo en el viejo sistema. Hasta qué punto el Estado estará en grado de garantizar la permanencia de un sistema así de asimétrico, y a través de qué recursos, queda como un problema abierto.

Por lo tanto, un primer escenario posible es el de una posible asimetría en las prestaciones del Estado social aseguradas por las únicas regiones que gozan de autonomía fiscal, que en Italia solamente son cuatro. Para las otras regiones, las garantías del Estado social (sobre todo instrucción y salud) son solo las aseguradas por la competencia legislativa estatal que, teniendo naturaleza transversal (como lo ha recordado la Corte en las sentencias núm. 282 y núm. 407 del 2002), se extienden también a las competencias regionales, sean aquellas concurrentes (pfo. $3^{\circ}$ ), residuales (pfo. $4^{\circ}$ ) o las exclusivas (pfo. $5^{\circ}$ ) que serán introducidas en el texto constitucional en caso que el proyecto de reforma constitucional (Bossi) sea aprobado.

\subsection{Fuentes locales}

Con relación a las autonomías locales, el nuevo cuadro no modifica el orden formal de los poderes normativos de los cuales las mismas son titulares. Respecto al anterior art. 128 Const., el art. 114 , pfo. $2^{\circ}$, Const. asegura la directa garantía constitucional de la potestad estatutaria de todos los entes autónomos. Además, en el art. 117, pfo. $4^{\circ}$, se garantiza a los entes locales la potestad reglamentaria para disciplinar la organización y desarrollo de las funciones a ellos atribuidas.

El estatuto de los entes locales conserva su naturaleza jurídica de acto administrativo general. No obstante, este ya no encuentra su legitimación en una ley general de la República -que fije los principios-sino más bien la encuentra directamente en la Constitución.

En aquellas partes no atinentes a la disciplina de las materias de competencia exclusiva estatal (art. 117 , pfo. $2^{\circ}$, letra p, Const.), el 
TUEL debe considerarse viciado de inconstitucionalidad sobrevenida, no entrando en la competencia estatal la intervención en materia de ordenamiento de los entes locales. No obstante, el mismo TUEL conserva su validez respecto a la ley regional competente para disciplinar las partes del ordenamiento local que no entran en el ámbito de la letra p) del art. 177 , pfo. $2^{\circ}$, Const. En consecuencia, dicha ley regional no podrá más que asumir la naturaleza de mera ley de principios.

Otra cosa es afirmar que, en ausencia de una nueva disciplina basada en una ley estatal (ejecutiva de la competencia exclusiva a que se refiere el art. 117 , pfo. $2^{\circ}$ letra p, Const. o de la ley regional de principio), el TUEL sea inmediatamente considerado como objeto de un efecto abrogativo, con la consecuente ilegitimidad constitucional sobrevenida en perjuicio de su vigencia. Para resolver dichas posibles antinomias, valen en general los criterios generales sobre la sucesión de las leyes en el tiempo y sobre la fuerza abrogatoria, que opera solo entre normas de igual jerarquía. Por lo tanto, se deduce que por el principio general del autocompletamiento del ordenamiento jurídico, solo una eventual sentencia de acogimiento de inconstitucionalidad por parte de la Corte Constitucional o la intervención del legislador (respectivamente nacional o regional, cada cual dentro de su ámbito de competencia) pueden determinar el efecto de caducidad de semejante disciplina, como de todas las otras que se encuentren vinculadas a la nueva repartición de competencias entre el Estado y las regiones.

Después de haber señalado la naturaleza y fuerza jurídica del estatuto de los entes locales - a la luz del reformado art. 114 , pfo. $2^{\circ}$, Const. y de la derogación del art. 128 Const.- es necesario reflexionar sobre la segunda potestad normativa reconocida a los entes locales. Se trata del pfo. $6^{\circ}$ del art. 117 Const., en aquella parte donde establece que "los ayuntamientos, las provincias y las ciudades metropolitanas tienen potestad reglamentaria para la disciplina de la organización y del desarrollo de las funciones a estos atribuidos". Esta disposición despliega sus efectos sobre un conjunto de relaciones entre fuentes: aquellas entre reglamentos locales y estatutos locales, aquellas entre reglamentos locales y leyes regionales, aquellas entre reglamentos locales y potestad reglamentaria regional, aquellas entre reglamentos locales y ley estatal $y$, en fin, entre reglamentos estatales y reglamentos regionales.

En cuanto a la primera relación, de la reforma constitucional no se derivan cambios sustanciales tales de modificar la naturaleza de los reglamentos locales. Dentro de su naturaleza de actos administrativos generales, ellos se encuentran subordinados al estatuto, que es competente -en el ámbito de la materia reservada al mismo por la ley estatal (letra p del art. 117 Const.) y a las eventuales leyes regionales (art. 117, pfo. $4^{\circ}$, Const.) - para fijar las modalidades de organización del ente mismo, particularmente en sus relaciones entre órganos. 
Igualmente fácil aparece la lectura de las relaciones entre reglamentos locales y ley estatal, cuestión en la que esta última disfruta de una competencia exclusiva para la regulación de las materias concernientes a la legislación electoral, a los órganos de gobierno o a las funciones fundamentales de los entes locales.

Un aspecto de discontinuidad respecto al ordenamiento anterior se refiere a las relaciones entre reglamentos locales y ley regional. El ordenamiento anterior asignaba a la competencia exclusiva de la ley estatal la entera disciplina del ordenamiento de las autonomías locales. Para asegurar la autonomía, dicha ley se calificaba como mera ley de principios, quedando excluida a la misma cualquier regulación de detalle, cuya competencia recaía en la materia estatutaria. El nuevo reparto normativo diseñado por la reforma constitucional transforma dicho orden, restando a la ley estatal, como ya se ha dicho, solo los ámbitos materiales a que se refiere la letra p) del art. 117 pfo. $2^{\circ}$ Const.

Por lo tanto, se concluye que con relación a todos los otros componentes del ordenamiento local (por ejemplo, regímenes de control, formas asociativas, etc.) es innovadoramente "reconocida" una competencia regional de tipo residual (sea legislativa que reglamentaria), atendido que en sede de legislación concurrente falta toda referencia competencial a la materia del ordenamiento local.

Los problemas de relación y de garantía de los ámbitos normativos constitucionalmente asignados a la potestad reglamentaria de las regiones y de los entes locales, respectivamente, se presentan con relación a la subsistencia de una competencia reglamentaria regional en materia de desenvolvimiento de las funciones "atribuidas" de los entes locales. En otros términos, frente a la potestad reglamentaria general (residual) de las regiones, parece que el ámbito material específico de competencia reglamentaria local (en el sentido del pfo. $6^{\circ}$ del art. 117 Const.) debe ser identificado en la "organización y (en el) desarrollo de las funciones a ellas atribuidas". Este último estaría limitado al aspecto organizativo y funcional interno al ente mismo y, particularmente, a las relaciones internas entre los órganos y entre estos y la población. Por el contrario, con respecto a las relaciones externas del ente, es decir respecto a las relaciones interinstitucionales, a la competencia estatal puede sumarse la competencia reglamentaria de las regiones en las materias limitadas a su propia competencia.

Una última consecuencia de la reforma se encuentra en la limitación de la potestad legislativa regional a los solos principios relativos al desarrollo de las funciones propias ("ley ligera" o limitada "a los principios básicos"). En consecuencia, queda excluida a la misma cualquier posibilidad de regulación de detalle, so pena de inconstitucionalidad por lesión de la esfera de autonomía local.

Un problema del todo especial es la vexata quaestio de las funciones de los entes locales que, con relación al ámbito material de regulación 
local, son "fundamentales", "propias", "atribuidas" y "conferidas" según la letra del nuevo texto constitucional.

El art. 118 Const., entendido en combinación con el art. 117 Const. (pfo. $2^{\circ}$, letra p, y pfo. $6^{\circ}$ ), origina importantes problemas interpretativos que hacen tan necesario un esfuerzo reconstructivo de la doctrina, una verdadera y propia negociación entre centro y periferia, como, en fin, una jurisprudencia constitucional aclaradora (que no obstante corre el riesgo de tener que "reescribir" la misma reforma constitucional con relación a la pertenencia de las funciones administrativas).

Las interpretaciones predominantes sobre las funciones "fundamentales" de los entes locales se basan sobre una posible ecuación entre funciones "fundamentales" y funciones "propias". La doctrina ha destacado como tal ecuación asigna a la ley estatal la determinación de dichas funciones, correspondiendo únicamente a la ley regional la asignación de las funciones "conferidas". Dicha orientación, sin embargo, no encuentra el respaldo del art. 118 , pfo. $2^{\circ}$, Const., que identifica la competencia legislativa en materia de funciones "conferidas" tanto en la ley estatal como en la ley regional. Respecto a tal hipótesis reconstructiva, parece más conforme al dato constitucional la lectura que ve en las funciones "fundamentales" aquellas caracterizadas por la indefectibilidad, deudora a su vez de la caracterización histórica y funcional de los entes locales, y posible de adscribir a "opciones ponderadas de política legislativa" (como históricamente consolidadas, evolucionadas y modificadas en el tiempo). Como se ve, la cuestión se hace relevante sobre todo por el hecho de que las diversas lecturas posibles que se darán a las funciones "fundamentales" por parte del legislador estatal son tales que, en el fondo, pueden llevar a un redimensionamiento sustancial del ámbito de la potestad legislativa regional, constituyendo una suerte de "título habilitante transversal" de interferencia y de condicionamiento de la misma.

En dicho sentido, algunas leyes resultan necesarias para dar una cumplida actuación a la reforma constitucional: a) la ley de transferencia de las funciones estatales según el art. 118 Const. (en el respeto de la reserva de ley a que se refiere el VIII de las disposiciones transitorias y finales de la Const.), b) la ley sobre procedimientos de participación de las regiones en la formación de los actos normativos comunitarios, c) la ley sobre determinación de los niveles esenciales de las prestaciones concernientes a los derechos civiles y sociales, d) la ley de actuación para la autonomía financiera, con fijación de los principios de coordinación de las finanzas públicas y del sistema tributario, y la institución del fondo de compensación, e) la ley sobre procedimientos relativos a los poderes gubernamentales sustitutivos, dentro del respeto a los principios de subsidiariedad y de colaboración leal y, en fin, $f$ ) la modificación de los reglamentos parlamentarios, con la actuación de las disposiciones a 
que se refiere el art. 11 de la ley constitucional núm. 3/ 2001, sobre integración de la Comisión parlamentaria para las cuestiones regionales con representantes de las regiones y de las autonomías locales.

\subsection{La autonomía financiera de las autonomías territtoriales}

El nuevo régimen de autonomía financiera territorial presenta importantes problemas interpretativos respecto a la relación entre el nuevo modelo de descentralización institucional y los principios fundamentales del ordenamiento constitucional, especialmente frente al principio de igualdad formal y sustancial y al principio de solidaridad "interpersonal" e "interterritorial". En dicho ámbito, la realización efectiva del nuevo regionalismo, y la garantía de la igual posición constitucional de los sujetos en materia de derechos (y de servicios), dependen en buena parte del modelo de financiamiento de las autonomías regionales y locales concretamente ejecutado sobre la base de los principios fijados por el nuevo art. 119 Const.

La "Constitución financiera" no define puntualmente las relaciones financieras entre los diversos niveles de gobierno, limitándose a regularlos a nivel de principio y reservando a la legislación estatal la respectiva disciplina de ejecución. En otros términos, la falta de una definición del peso de cada una de las fuentes de ingreso regional hace elástico el modelo constitucional de relaciones financieras intergubernativas. Se desprende, entonces, que parámetros constitucionales así de generales entregan al legislador una función ampliamente discrecional.

El art. 119 constitucionaliza el principio de la territorialidad del impuesto. Por lo tanto, cada Región -como cualquier otro ente autónomo de la República- financia integralmente las funciones públicas a ella atribuidas con recursos propios o tributos propios, o también mediante la coparticipación en la recaudación de los tributos del erario público y el mecanismo de corrección dirigido a compensar las diferentes capacidades fiscales interterritoriales (de las regiones y de los entes autónomos de la República).

Los efectos redistributivos del diseño constitucional de finanzas regionales originan interrogantes. En efecto, aun previéndose mecanismos compensatorios (indefinidos en entidad y peso específico), no está ausente un posible riesgo de ulterior polarización entre áreas territoriales "ricas" y "pobres", lo que puede incrementar el grado de desigualdad interterritorial e interpersonal.

El nuevo texto del art. 119 Const. prevé la atribución de autonomía financiera de ingresos y de gastos para los ayuntamientos, las provincias, las ciudades metropolitanas y las regiones (pfo. $1^{\circ}$ ). Dichos entes "establecen y aplican tributos e ingresos propios, en armonía con la Constitución y según los principios de coordinación de las finanzas públicas 
y del sistema tributario", y disponen además de "coparticipación en la recaudación de tributos del erario referibles a su territorio" (pfo. $2^{\circ}$ ). Además, al lado de dichos flujos se ha dispuesto la institución de "un fondo de compensación sin vínculos de destinación, para los territorios con menor capacidad fiscal por habitante" (pfo. $3^{\circ}$ ). Con tal disposición de clausura, se establece que los flujos financieros derivados de los recursos autónomos (tributos propios y coparticipación) y del fondo de compensación permiten a las autonomías territoriales "financiar integralmente las funciones públicas a ellas atribuidas" (pfo. $4^{\circ}$ ). A dichas disposiciones generales se añaden asignaciones complementarias por las cuales "el Estado destina recursos adicionales y efectúa intervenciones especiales" en favor de determinados entes territoriales con el fin de "promover el desarrollo económico, la cohesión y la solidaridad social, remover los desequilibrios económicos y sociales, favorecer el ejercicio efectivo de los derechos de la persona, o para proveer a finalidades diversas del normal ejercicio de sus funciones".

Con respecto a la anterior formulación constitucional se producen significativas implicaciones constitucionales. En primer lugar, destaca la voluntad del legislador de reforma por ampliar la esfera propia de la potestad legislativa tributaria regional, si bien dentro del ámbito de los principios generales establecidos por la legislación estatal en las materias de coordinación financiera y del sistema tributario y, en todo caso, dentro del respeto a la autonomía reconocida a los otros entes territoriales. Por otro lado, basándose en el pfo. $3^{\circ}$ del art. 117 Const., la coordinación de las finanzas públicas y del sistema tributario, junto a la armonización de los presupuestos públicos, entran en el ámbito material objeto de la potestad legislativa concurrente; la potestad legislativa relativa a dichas materias debe, por lo tanto, ajustarse a la Constitución y respetar los vínculos impuestos por el ordenamiento comunitario y por las obligaciones internacionales (art. 117, pfo. $1^{\circ}$, Const.).

De la combinación dispuesta por tales disposiciones se deriva un doble orden de consideraciones que se refieren, por una parte, a la potestad tributaria de las regiones y, por otra, a las obligaciones de naturaleza supranacional. En relación al primero se presenta un problema vinculado con la definición del grado e intensidad de la potestad legislativa regional en materia financiera con relación al perfil tributario/impositivo y, en consecuencia, a los espacios de autonomía para determinar los tributos locales.

Debe destacarse, por un lado, que el ámbito material concerniente al "sistema tributario y contable del Estado" se encuentra reservado a la competencia legislativa exclusiva estatal (art. 117, pfo. $2^{\circ}$ letra e, Const.), en confirmación del carácter unitario del ordenamiento tributario (art. 53). Por otro lado, según se encuentra establecido en el pfo. $3^{\circ}$ del art. 117 Const., la materia relativa a la "coordinación de las finanzas públicas 
$y$ del sistema tributario" entra dentro de la competencia concurrente. En este sentido, puede preverse una implicación entre los niveles de gobierno territorial y las decisiones legislativas nacionales. En definitiva, el modelo tributario de la autonomía regional debe ajustarse en todo caso al principio general de la unidad del ordenamiento y a los principios establecidos por ley estatal en orden a la configuración de los tributos (sobre la reserva de ley a que se refieren los arts. 2, 23 y 53 Const.), mientras que a las regiones, además de concurrir a las decisiones político-legislativas, corresponde el diseño de "un sistema tributario" -a ser definido por la ley regional-o bien "establecer y aplicar tributos e ingresos propios".

Con respecto al principio de la comunitarización de la Constitución, se deduce que las políticas presupuestarias, monetarias, de endeudamiento público y fiscales deben conformarse a los principios y a las reglas de la Unión Europea, establecidos para las modalidades de recaudación de los recursos financieros, como también del gasto y de los respectivos controles financieros destinados a preservar el equilibrio financiero total. Por lo tanto, para las materias citadas, el ejercicio de la potestad legislativa estatal-regional resulta condicionado por el vínculo comunitario. Parece evidente que la autonomía financiera de los entes autónomos, señalados en el art. 119 , pfo. $1^{\circ}$, Const., debe conformarse a las obligaciones de la normativa comunitaria.

Además, con la previsión de la coparticipación en la recaudación de tributos "indeterminados" del erario referibles a su territorio se introduce una regionalización de este tipo de impuestos, con lo que se prevé que la recaudación tributaria de conjunto debe ser primeramente repartida sobre base regional y luego asignada -según la alícuota de coparticipación- a cada una de las regiones y entes locales. Con dicha disposición, se asegura certeza y suficiencia financiera a las áreas territoriales caracterizadas por elevadas capacidades fiscales. A la inversa, con la locución "referibles a su territorio" toma cuerpo la mayor innovación de la reforma en cuanto indica cómo repartir la recaudación de un tributo estatal entre las regiones. Dicha expresión, por lo tanto, concurre a expresar el nuevo sistema de relaciones financieras entre centro y periferia, en suma, el modelo de financiación de los gobiernos territoriales, fundándose sobre el principio según el cual los recursos derivados de la coparticipación en la recaudación de los tributos del erario van a las regiones sobre cuyo territorio es referible la recaudación.

Esta última indicación confluye a individualizar la estructura compensatoria, además de adaptar los principios establecidos por el art. 119 Const. a los diversos regímenes de competencia regional y al respectivo financiamiento.

A dicha disposición se agrega la institución, mediante una ley estatal, de un "fondo de compensación sin vínculos de destinación" (pfo. $3^{\circ}$ ) 
para algunas autonomías territoriales, sobre la base del criterio exclusivo representado por la "menor capacidad fiscal por habitante", sin definir criterios ulteriores que definirían mejor el costo de los servicios.

Además, debido a propósitos constitucionales y en todo caso por finalidades "diversas del normal ejercicio de sus funciones", con la nueva formulación el legislador constitucional ha dispuesto la posibilidad a cargo del Estado de destinar "recursos adicionales" y de efectuar "intervenciones especiales" (pfo. $5^{\circ}$ ) en favor de los entes territoriales, en caso de que concurran determinadas condiciones, mientras que en el texto anterior podían asignarse a determinadas regiones, mediante ley de "contribuciones especiales" destinadas "a fines determinados, y particularmente para valorizar el Mezzogiono y las Islas".

A la luz de dichas disposiciones, resulta de primera consideración la correspondencia entre las funciones ejercitadas por las autonomías territoriales y la dotación de recursos necesarios para financiarlas, en razón de la ruptura del principio de paralelismo entre las funciones legislativas y las funciones administrativas. Una vez establecida la correspondencia entre la devolución de los recursos y el financiamiento integral de las funciones a ellas atribuidas, el art. 119 Const. parece delinear un modelo de reparto financiero "variable", en la medida que un modelo así configurado necesita de una remodulación continua, no más dependiente de la referencia a un constante reparto de la potestad legislativa. Por otra parte $-\mathrm{y}$ no obstante no se encuentre en el art. 119 una referencia expresa a "la determinación de los niveles esenciales de las prestaciones concernientes a los derechos civiles y sociales que deben ser garantizados en todo el territorio nacional" (art. 117, pfo. $2^{\circ}$ letra m, Const.)- dicha problemática aparece central, de modo que se presentan delicados problemas interpretativos y de actuación sobre la adecuación del modelo de financiamiento diseñado conforme a las exigencias de compensación. Se desprende así que la determinación de los "niveles esenciales" sobre todo el territorio nacional y su respectiva garantía se encuentran condicionados por la entidad de los fondos destinados a los fines de compensación y por la posibilidad de poder decidir sobre la distribución de los recursos financieros de los entes autónomos.

\section{BibLIOGRAFÍA ESENCIAL}

Sobre la nueva arquitectura constitucional de la reforma: AA. VV. (a cura di S. Gambino), Il nuovo ordinamento regionale, Milano, 2003; AA. Vv. (a cura di S. Gambino), Diritto regionale e degli enti locali, Milano, 2003; AA. Vv. (Seminario A.I.C.), Il nuovo Titolo V della Parte II della Costituzione, Milano, 2003; S. Mangiameli, La riforma del regionalismo italiano, Torino, 2002; A. Anzon, I poteri delle Regioni dopo la riforma 
costituzionale, Torino, 2002; B. Caravita, La Costituzione dopo la riforma del Titolo V, Torino, 2002; AA. Vv. (a cura di T. Groppi - M. Olivetti), La Repubblica delle autonomie, Torino, 2001; AA. Vv. (a cura di A. Piraino) La funzione normativa di Comuni, Province e Città metropolitane nel nuovo sistema costituzionale, Palermo, 2002; A. Ruggeri, Le fonti di diritto regionale: ieri, oggi, domani, Torino, 2001; M. Carli - C. Fusaro, Elezione diretta del Presidente della Giunta regionale e autonomia statutaria elle Regioni, Bologna, 2002.

Sobre la potestad legislativa regional: AA. Vv., "La riforma del Titolo V, parte II della Costituzione", en Foro Italiano 2001 n. 7-8; P. Caretti, "Il nuovo assetto delle competenze normative", en AA. Vv. (a cura di G. Berti - G. C. De Martin), Le autonomie territoriali: dalla riforma amministrativa alle riforma Costituzionale, Milano 2001; P. Cavaleri, Diritto regionale, Padova, 2003; V. Cerulli Irelli, "Contributo" en AA. Vv. (a cura di G. Berti - G. C. De Martin), Le autonomie territoriali ... cit.; A. D'Atena, "La difficile transizione. In tema di attuazione della riforma del Titolo V", en Le Regioni, 2002, n. 2/3; M. Dogliani, "Il nuovo assetto delle competenze normative", en AA. Vv. (a cura di G. Berti - G. C. De Martin), Le autonomie territoriali ... cit.; T. Martines - A. Ruggeri - C. Salazar, Lineamenti di diritto regionale, Milano 2002; M. Luciani, "Le nuove competenze legislative delle regioni a Statuto ordinario. Prime osservazioni sui principali nodi problematici della legge cost. n. 3/2001", Intervento Convegno A.I.C., Bologna 14 gennaio 2002; L. Paladin L., Diritto regionale, Padova 2000; S. Panunzio, Audizione del Presidente A.I.C. al Senato della Repubblica sulla revisione del Titolo V, parte II della Costituzione, 20 de noviembre de 2001, en: Senato della Repubblica, Indagine conoscitiva I Commissione Affari Costituzionali, $7^{\circ}$ relación estenográfica, sesión del martes 20 de noviembre de 2001; C. Pinelli, L'ordinamento repubblicano nel nuovo impianto del Titolo $V$, in AA. Vv. (a cura di S. Gambino), Il nuovo ordinamento regionale, Milano, 2003; G. Rolla, Diritto regionale e degli enti locali, Milano 2002; A. Ruggeri, Le fonti del diritto regionale: ieri, oggi, domani, Torino, 2001; L. Torchia, "La potestà legislativa residuale delle regioni", en Le Regioni, 2002, n. $2 / 3$.

Sobre los limites a la potestad legislativa regional derivados de la conformidad con las obligaciones establecidas por el derecho internacional y comunitario: U. Allegretti, "Autonomia regionale e unità nazionale", en Le Regioni, 1995, p. 15; G. Berti, "Commento art. 5", en G. Branca (a cura di), Commentario della Costituzione, Roma-Bari, pp. 277 ss.; A Spadaro, "Sui principi di continuità dell'ordinamento, di sussidiarietà e di cooperazione fra Comunità/Unione europea, Stato e Regioni", en Rivista trimestrale di diritto pubblico, 1994, pp. 1041 ss.; A Pizzorusso, 
"Delle fonti del diritto", en Commentario del Codice civile, Bologna-Roma, 1977 , p. 277; A. Ruggeri, "Potestà legislativa primaria e potestà "residuale" a confronto (nota minima a Corte cost. n. 48 del 2003", en el sitio <federalismi.it>, 2003; L. Paladin, Le fonti del diritto italiano, Bologna, 1996, p. 325; V. Crisafulli, "Legge di nazionalizzazione, decreti delegati di trasferimento e ricorsi regionali", en Giurisprudenza costituzionale, 1964, pp. 118 ss.; P. Caretti, "L'assetto dei rapporti tra competenza legislativa statale e regionale, alla luce del nuovo Titolo V della Costituzione: aspetti problematici, en Le Regioni, 2001, p. 1229; G. Caia, "Il problema del limite dell'interesse nazionale nel nuovo ordinamento", en el sitio <federalismi.it>, 2003; A. Anzon, I poteri delle Regioni dopo la riforma costituzionale, Torino, 2002, pp. 155 ss.

Sobre los límites a la potestad legislativa regional derivados de la obligación de respetar los niveles esenciales de las prestaciones concernientes a los derechos civiles y sociales a garantizar sobre todo el territorio nacional: $\mathrm{G}$. U. Rescigno, "I diritti civili e sociali fra legislazione esclusiva dello Stato e delle Regioni", en AA. Vv. (a cura di S. Gambino), Il nuovo ordinamento regionale in Italia. Competenze e diritti, Milano, 2003; A. Ruggeri, "Neo-regionalismo e tecniche di regolazione dei diritti sociali", en Diritto e società, 2001, n. 2; A. Ruggeri, "La riforma costituzionale del Titolo V e i problemi della sua attuazione, con specifico riguardo alle dinamiche della normazione ed al piano dei controlli", en Il nuovo Titolo V della parte II della Costituzione (Seminario A.I.C. del 14/1/2002, en el sitio <www.associazionedeicostituzionalisti.it>; M. Luciani, "La tutela costituzionale dei livelli essenziali di assistenza", en "I livelli essenziali di assistenza nella Costituzione. Doveri dello Stato, diritti dei cittadini", Lega delle autonomie, Roma, 12 marzo 2002 (paper); I. Massa Pinto, "Contenuto minimo essenziale dei diritti costituzionali e concezione espansiva della Costituzione", en Diritto pubblico, 2001, n. 3; I. Massa Pinto, "La discrezionalità politica del legislatore fra tutela costituzionale del contenuto essenziale e tutela ordinaria caso per caso dei diritti nella più recente giurisprudenza della Corte costituzionale", en Giurisprudenza costituzionale, 1998, 2; O. Chessa, "La misura minima essenziale dei diritti sociali: problemi e implicazioni di un difficile bilanciamento", en Giurisprudenza costituzionale, 1998; O. Chessa, "Bilanciamento ben temperato o sindacato esterno di ragionevolezza? Note sui diritti inviolabili come parametro del giudizio di costituzionalità", en Giurisprudenza costituzionale, 1998, n. 6; G. Zagrebelsky, Il diritto mite, Torino, 1992.

Sobre la potestad reglamentaria de las regiones: C.E. Gallo, Le fonti del diritto nel nuovo ordinamento regionale. Una prima lettura, Torino, 2001; V. Onida, "Regolamenti regionali", en Enciclopedia giuridica Treccani, 
XXVI, Roma, 1991; G. Tarli Barbieri, "La potestà regolamentare delle Regioni dopo la legge cost. n. 1/1999", en Le Regioni, 2000; R. Bin, "La funzione amministrativa nel nuovo Titolo V della Costituzione", en Le Regioni, 2002; P. Caretti, "Fonti statali e fonti locali dopo la riforma del titolo V della Costituzione", en Le Regioni, 2002; A. Ruggeri, "La ricomposizione delle fonti in sistema, nella Repubblica delle autonomie, e le nuove frontiere della normazione", en Le Regioni, 2002.

Sobre la forma de gobierno regional: V. Angiolini, Gli organi di governo della Regione, Milano, 1983; R. Bin R., "Reinventare i Consigli", en Il Mulino, 2000, n. 3; A. D'Atena, "La nuova autonomia statutaria delle Regioni", en Rassegna parlamentaria, 2000; U. De Siervo, Gli statuti delle Regioni, Milano, 1974; C. Fusaro, "La legge elettorale e la forma di governo regionale", en AA. Vv. (a cura di A. Barbera - L. Califano), Saggi e materiale di diritto regionale, Bologna, 1997; T. Groppi, "Quale garante per lo Statuto regionale", en AA. Vv., La potestà statutaria delle Regioni nella prospettiva della riforma della Costituzione. Temi rilevanti e profili comparati, Milano, 2001; T. Martines - A. Ruggeri, Lineamenti di diritto regionale, Milano, 1997; T. Martines - A. Ruggeri - C. Salazar, Lineamenti di diritto regionale, Milano, 2002; L. Paladin, Diritto regionale, Padova, 2000; L. Paladin, Le fonti del diritto italiano, Bologna, 1996; A. Spadaro, "I "contenuti" degli Statuti regionali (con particolare riguardo alle forme di governo)", en AA. Vv. (a cura di A. Ruggeri - G. Silvestri), Le fonti di diritto regionale alla ricerca di una nuova identità, Milano, 2001; G. Tarli Barbieri, "I referendum su leggi e provvedimenti amministrativi della Regione", en AA. Vv. (a cura di M. Carli), Il ruolo delle Assemblee legislative. Vol. I, La nuova forma di governo delle Regioni, Torino, 2001; R. Tosi, "Le "leggi statutarie" delle Regioni ordinarie e speciali: problemi di competenza e di procedimento", en AA. Vv., Le fonti di diritto regionale ... cit.

Sobre el Estado regional asimétrico y diferenciado: L. Antonini, Il regionalismo differenziato, Milano, 2000; G. D'Ignazio, "Asimmetrie e differenziazioni regionali dopo la riforma del titolo V della Costituzione", en AA. Vv. (a cura di S. Gambino), Il 'nuovo' ordinamento regionale, Milano, 2003; J. F. Lopez Aguilar, Lo Stato autonomico spagnolo, Padova, 1999; F. Palermo, "Il regionalismo differenziato", en AA. VV. (a cura di T. Groppi - M. Olivetti), La Repubblica delle autonomie, Torino, 2001; P. Pernthaler, Lo Stato federale differenziato, Bologna, 1998.

Sobre las regiones de Derecho especial previstas por el art. 116 Const.: A. D'Atena, "Dove va l'autonomia regionale speciale?", en Rivista di diritto costituzionale, 1999; M. Luciani, "Le regioni a statuto speciale nella trasformazione del regionalismo italiano (con alcune considera- 
zioni sulle proposte di revisione dello Statuto della Regione Trentino Alto Adige)", en Rivista di diritto costituzionale, 1999; G. Moschella, "L'incerta prospettiva delle Regioni speciali", en AA. Vv. (a cura di S. Gambino), Il 'nuovo' ordinamento regionale, Milano, 2003; A. Pizzorusso, "Regioni speciali: motivazioni storiche ed esigenze attuali", en Quaderni regionali, 1988; A. Ruggeri, "Elezione diretta dei Presidenti regionali, riforma degli statuti, prospettive della 'specialità", en Rivista di diritto costituzionale, 1999, p. 231 y del mismo A.: "L'autonomia legislativa della Regione siciliana dopo la riforma del titolo V, e le prospettive della specialità", en Idem, "Itinerari" di una ricerca sul sistema delle fonti, Torino, 2003, vol. II. 